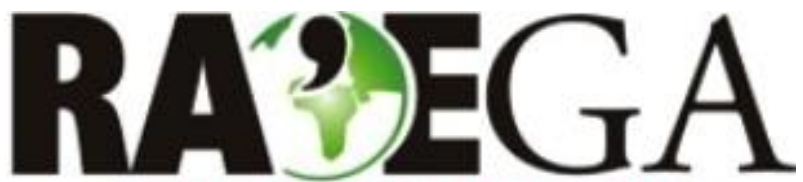

O ESPAÇO GEOGRÁFICO EM ANÁLISE

\title{
EMPREGO DE TÉCNICAS GEOMORFOMÉTRICAS NA IDENTIFICAÇÃO DE PADRÕES DE RELEVO
}

\author{
GEOMORFOMETRIC TECHNIQUES TO IDENTIFICATION OF RELIEF PATTERNS
}

\author{
Willian Bortolini ${ }^{1}$, Claudinei Taborda da Silveira ${ }^{2}$, Ricardo Michael Pinheiro Silveira ${ }^{3}$ \\ RESUMO
}

Técnicas geomorfométricas são cada vez mais aplicadas à cartografia geomorfológica, devido à facilidade de mensurações e extrações de parâmetros do relevo calculados a partir dos Modelos Digitais de Elevação (MDEs) que favorecem o mapeamento geomorfológico. Nesse contexto, o objetivo do trabalho foi aplicar essas técnicas como proposição para o mapeamento de padrões de relevo na escala 1:100.000, em conformidade com o quarto nível hierárquico da proposta taxonômica de Ross (1992). Para isso foram calculados os atributos topográficos do MDE amplitude altimétrica e média da declividade, utilizando raio circular de 750 metros e, posteriormente, discretizados em classes e combinados por meio de álgebra de mapa para a identificação dos padrões de relevo. 0 recorte geográfico adotado foram as cartas topográficas Pato Branco (MI2682) e Clevelândia (MI2683), localizados no sudoeste paranaense. Os padrões de relevo preliminarmente mapeados foram submetidos à verificação em campanha de campo, que ofereceu apoio para conferência e aperfeiçoamento. Em seguida foi estabelecida a menor unidade mapeável com dimensão de $1767,15 \mathrm{~km} 2$, assim áreas inferiores a esse valor foram agrupadas às unidades vizinhas. Como resultado foram identificado seis padrões de relevo: colinas, morrotes, morros, morros declivosos, e serras; submetidos ao controle por dissecação homogênea ou dissecação estrutural. A proposição ofereceu um método para identificar os padrões de relevo no quarto táxon, cuja aplicação foi satisfatória, demonstrando fidedignidade com a configuração geomorfológica da área de estudo.

PALAVRAS-CHAVE: Geomorfometria; Cartografia Geomorfológica; Mapeamento Geomorfológico; Modelo Digital de Elevação

\begin{abstract}
The geomorphometric techniques are increasingly applied to geomorphological cartography, due to the ease of measurements and extractions of topographic attributes calculated from Digital Elevation Model (MDE) that favor morphological recognition. In this context, the objective of the work was to apply geomorphometric techniques in the construction of a method for the mapping of relief patterns in the scale 1: 100,000, according to the fourth hierarchical level of the taxonomic proposal of Ross (1992). For this, the MDE was elaborated and the topographic attributes were calculated for the elevation and mean slope amplitude, using a circular radius of $750 \mathrm{~m}$, and later discretized in classes and combined by means of map algebra for the identification of relief patterns. The studied section covers the area of the topographic map Pato Branco (MI2682) and Clevelândia (MI2683), in southwest of Paraná. The preliminarily mapped landform were submitted to the field campaign verification, which offered support to identify the relief and redefinition of the discretization intervals of the topographic attributes. Then, the smallest mappable unit with a dimension of $1767.15 \mathrm{~km} 2$ was established, so areas smaller than this value were grouped to neighboring units. As a result, six relief patterns: hills, morrotes, hills, sloping hills, and hills; Submitted to control by homogeneous dissection or structural dissection. The proposition offered a method to identify the relief patterns in the fourth taxon, whose application was satisfactory, demonstrating reliability with the geomorphological configuration of the study area.
\end{abstract}

KEY-WORDS: Geomorphometry; Geomorphological cartography; Geomorphological mapping; Digital Elevation Model

Recebido em: 12/04/2017

Aceito em: 20/06/2017

\footnotetext{
${ }^{1}$ Universidade Federal do Paraná ,Curitiba/PR, e-mail: willianbortolini@gmail.com

2 Universidade Federal do Paraná,Curitiba/PR, e-mail: claudinei.ufpr@yahoo.com.br

${ }^{3}$ Universidade Federal do Paraná ,Curitiba/PR, e-mail: ricardomichaelps@gmail.com
} 


\section{EMPREGO DE TÉCNICAS GEOMORFOMÉTRICAS NA IDENTIFICAÇÃO DE PADRÕES DE RELEVO}

\section{INTRODUÇÃO}

A cartografia geomorfológica se constitui como um dos principais instrumentos de espacialização dos fatos geomorfológicos, permitindo a representação das formas de relevo e suas relações com a estrutura e processos, que podem auxiliar na identificação da gênese das formas identificadas (CASSETI, 2005; SMITH et al., 2008). Este instrumento possui importância no planejamento ambiental (ROSS, 1990), além de disponibilizar informações importantes para trabalhos vinculados às Ciências da Terra (COLTRINARI, 2011).

Devido à complexidade da representação relevo e ao fato da superfície terrestre ser composta por formas que variam em função da escala de análise, Ross (1992) desenvolveu uma proposta de classificação taxonômica geomorfológica, considerando o relevo em seis diferentes táxons, produtos do antagonismo entre os processos endógenos e exógenos. A proposta segue contribuições de Mescerjakov (1968) e Gerassimov e Mescherikov (1968), com os conceitos de morfotectura, morfoestrutura e morfoescultura.

Os táxons são: 10 táxon: unidades morfoestruturais; 20 táxon: unidades morfoesculturais; 3o táxon: unidades de padrões de formas semelhantes, que são conjuntos de formas menores do relevo, que apresentam rugosidade topográfica ou grau de dissecação semelhante; 40 táxon: tipos de formas de relevo, que são formas individualizadas dentro de cada Unidade de Padrão de Formas Semelhantes, podendo ser de agradação ou de denudação, sendo semelhantes entre si tanto na morfologia quanto na morfometria, ou seja, tanto formato, quanto na idade; 50 táxon: vertentes ou setores de vertentes pertencentes a cada uma das formas individualizadas do relevo e 60 táxon: formas de relevo menores, geradas ao longo das vertentes por processos geomórficos atuais, e principalmente por indução antrópica.

Baseado na proposta taxonômica de Ross (1992), foram realizados os mapas geomorfológicos de São Paulo (ROSS; MOROZ, 1997) e o mapeamento geomorfológico do estado do Paraná (SANTOS et al., 2006), sendo que o último representou os três primeiros táxons geomorfológicos na escala 1:250.000, caracterizando um marco fundamental na pesquisa geomorfológica paranaense, devido ao fato de ser o primeiro mapeamento sistemático do relevo no estado

Outra proposta de mapeamento geomorfológico é a do IBGE (2009), que tem como princípio básico o ordenamento dos fatos geomorfológicos segundo uma classificação temporal e espacial, distinguindo os modelados como unidade básica e seus grupamentos hierarquicamente relacionados. A individualização destes conjuntos de feições é realizada levando em consideração parâmetros como fatores causais, responsáveis pela evolução das formas do relevo e pela composição da paisagem no decorrer do tempo geológico. Os táxons identificados de acordo com a ordem decrescente de grandeza são: a) Domínios Morfoestruturais; b) Regiões Geomorfológicas; c) Unidades Geomorfológicas; d) Modelados; e) Formas de Relevo Simbolizadas.

Uma série de trabalhos mapearam padrões de relevos levando como base na proposta metodológica de Ross (1992) e do IBGE (2009). Os padrões foram identificados a partir de fotointerpretação, caso do mapeamento realizado por Ross e Moroz (1997); ou fotointerpretação associada à interpretação de atributos topográficos gerados a partir de MDEs, no caso dos mapeamentos realizados por Carneiro e Souza (2003), Silva (2010), Augustin et al. (2011) e CPRM e IPT (2014).

Alguns trabalhos utilizaram, de modo auxiliar à fotointerpretação, parâmetros de classificação de padrões de relevo ou modelados que consideram a amplitude altimétrica predominante ou local e declividade predominante. São exemplos desses o mapeamento de padrões de relevo de Ponçano et al. (1981), Carneiro e Souza (2003) e CPRM e IPT (2014).

Entretanto, a complexidade na análise e representação do relevo demanda a utilização de métodos auxiliares. Os métodos e técnicas 


\section{EMPREGO DE TÉCNICAS GEOMORFOMÉTRICAS NA IDENTIFICAÇÃO DE PADRÕES DE RELEVO}

amparados na geomorfometria se apresentam como ferramenta aplicável à cartografia geomorfológica devido à sua capacidade de otimizar o processo de mapeamento com critérios quantitativos previamente estabelecidos.

Assim, a geomorfometria se tornou uma moderna abordagem analítico-cartográfica para representar a superfície da Terra nas últimas décadas (TOBLER, 2000). Ela tem como operação fundamental a extração de parâmetros de Modelos Digitais de Elevação (MDEs), descrevendo morfometricamente a superfície terrestre (PIKE et al., 2009). Segundo Dikau (1989), o mapeamento geomorfológico pautado em aspectos quantitativos deve proporcionar uma classificação objetiva das feições do relevo formadas por componentes definíveis.

Segundo Pike et al. (2009, p. 6) MDE conceitua-se como "um mapa matricial ou vetorial mostrando a altitude da superfície da Terra sobre o nível médio do mar ou sobre algum outro referencial horizontal". Estes modelos podem ter estrutura irregular (caso das estruturas em redes de triângulo) ou estrutura regular (caso das estruturas matriciais), sendo a última a mais utilizada recentemente por possibilitar os cálculos executados por meio de janelas móveis.

Os MDEs são utilizados no mapeamento e modelagem de paisagens naturais devido à sua riqueza de medidas, mensurações e objetos que podem ser derivados pela análise automatizada dos dados de elevação (HENGL; MACMILLAN, 2009). Segundo Zhou (2004) os MDEs fornecem parâmetros derivados (também conhecidos como atributos topográficos) como declividade, amplitude altimétrica, aspecto, curvaturas, entre outros (WILSON; GALLANT, 2000; HENGL; REUTER, 2009).

$\mathrm{Na}$ perspectiva de aplicação da geomorfometria como ferramenta para o mapeamento de formas de relevo, algumas propostas obtiveram destaque, como o trabalho de classificação de feições de relevo desenvolvida por Wood (1996), o índice de posição topográfico (IPT) por Weiss (2001), a classificação hierárquica de formas de relevo adaptada para o ambiente informatizado por Dikau (1991), a classificação não-supervisionada de formas de relevo de Iwahashi e Pike (2007) e a segmentação de formas elementares por Minar e Evans (2008).

No Brasil, cabe mencionar alguns exemplos de aplicações realizadas: emprego do índice de concentração da rugosidade (ICR), proposta de Sampaio e Augustin (2014), aplicado por Souza e Sampaio (2010) e Silveira et al. (2012) em estudo comparativo com mapeamento de unidades geomorfológicas; aplicação de método de classificação não-supervisionada de formas de relevo por meio de árvore de decisões por Silveira et al. (2014) no Paraná e Trentin el al. (2015) em uma bacia hidrográfica situada no oeste do Rio Grande do Sul; classificação geomorfométrica automatizada por Vasconcelos et al. (2012) aplicada no Parque Nacional Serra da Canastra/MG; emprego da classificação hierarquizada no mapeamento de formas de relevo por Tinós et al. (2014) no planalto de Poços de Caldas/MG, Silveira e Silveira (2015) em toda a abrangência do estado do Paraná e Silveira e Silveira (2016) na região central da Serra do Mar Paranaense; uso do conceito de geomorphons por Robaina et al. (2016) para classificação automática de formas de relevo no estado do Rio Grande do Sul.

Nesse contexto, o presente trabalho tem como objetivo apresentar a proposição de técnicas geomorfométricas para classificar padrões de relevo que visam atender a representação morfológica equivalente ao $4 \underline{0}$ nível taxonômico da proposta metodológica de Ross (1992) para mapeamento geomorfológico, cujo método foi desenvolvido no âmbito do "Projeto de Mapeamento do Estado do Paraná apoiado em análise digital do relevo", com recurso de fomento do Conselho Nacional de Desenvolvimento Científico e Tecnológico (CNPq), da chamada MCTI/CNPq/Universal 2014. A aplicação foi realizada em duas folhas das cartas topográficas do mapeamento sistemático na escala 1:100.000. 


\section{EMPREGO DE TÉCNICAS GEOMORFOMÉTRICAS NA IDENTIFICAÇÃO DE PADRÕES DE RELEVO}

\section{CARACTERIZAÇÃO DA ÁREA DE ESTUDO}

$A$ área de estudo deste trabalho abrange as cartas Pato Branco (MI 2682) e Clevelândia (MI 2683), na escala 1:100.000, localizadas na região sudoeste do estado do Paraná. Ambas abrangem parte do estado de Santa Catarina, entretanto trabalhou-se apenas com as áreas do território paranaense, que somam 4572,24 km2.

As cartas contemplam os municípios de Pato Branco, Vitorino, Mariópolis, Renascença, Bom Sucesso do Sul, Honório Serpa, Coronel Vivida, Clevelândia, Itapejara d'Oeste, Francisco Beltrão, Marmeleiro, Mangueirinha, Palmas, Coronel Domingos Soares e Reserva do Iguaçu.

Em aspectos geológicos, o recorte está inserido na Formação Serra Geral, que pertence ao grande compartimento da Bacia do Paraná, sendo constituída por extensos derrames de rochas ígneas, predominantemente basaltos, da idade jurássica-cretácica (MINEROPAR, 2001), que estão associados aos estágios iníciais da separação do continente de Gondwana e a formação do oceano Atlântico. Destes derrames, distintos grupos geoquímicos de basaltos podem ser identificados (MILANI et al., 1998).

Há três diferentes grupos de orientações estruturais na Bacia do Paraná: NW-SE, NE-SW e E-W. Os dois primeiros grupos possuem maior relevânica, podendo ser falhas simples ou extensas zonas de falhas, que são zonas de fraqueza antiga que foram recorrentemente ativas durante a evolução da bacia. As falhas de direção NW estão intensivamente cortadas por diques de diabásio, tendo sido fortemente reativadas durante o quebramento juro-cretáceo do Gondwana. Este quebramento ativou as falhas preexistentes e criou novas falhas paralelas, promovendo o condicionamento de milhares de corpos ígneos intrusivos e a extrusão do mais volumoso derrame de lava do planeta. Por sua vez, as falhas de direção NE não apresentam feições de intrusão por diques de diabásio, bem como não foram reativadas no quebramento. Estas diferenças evolutivas entre os dois grupos explicam a distinção no arranjo estrutural entre ambos. São exemplos do padrão estrutural das falhas de direção NW a falha Curitiba/Maringá (onde o Arco de Ponta Grossa está totalmente ineserido), a falha do Rio Piqueiri, Guarapira e Cândido Abreu/Campo Mourão. Já as falhas de direção NE são compostas por uma única zona de falha retilínea (com exceção das zonas das falhas da Lancinha/Cubatão e Transbrasiliano) (ZALÁN et al., 1987).

Menos compreendidos que as demais, os lineamentos $\mathrm{E}-\mathrm{W}$ possuem desenvolvimento a partir do Triássico, podendo ter uma ligação qualquer com o desenvolvimento do Atlântico Sul. Também domos de pequeno porte, horst e grabens assim como falhas listricas reversas são encontradas na bacia, podendo na maior parte serem relacionados a corpos ígneos intrusivos em sub-superfície ou à reativação de zonas de falhas importantes (ZALÁN et al., 1987).

Conforme Mineropar (2013), foram mapeados na Formação Serra Geral, no estado do Paraná, lineamentos com persistência em três direções (Figura 01): a) Lineamentos N50o - 70oE, coincidente com a zona de cisalhamento principal, sendo o sistema Lancinha - Morro Agudo (falhas transcorrentes, retilíneas e anostomosadas); b) Lineamentos N10o - 20oW, sendo o setor das direções das estruturas distensionais ou fraturas de relaxamento; c) Lineamentos $\mathrm{N} 30 \mathrm{o}$ - 60oW, sendo o setor que compreende as estruturas do Arco de Ponta Grossa, diques isolados ou em enxames que existem na Bacia do Paraná e que estão relacionados com o magmatismo básico mesozoico. 


\section{EMPREGO DE TÉCNICAS GEOMORFOMÉTRICAS NA IDENTIFICAÇÃO DE PADRÕES DE RELEVO}

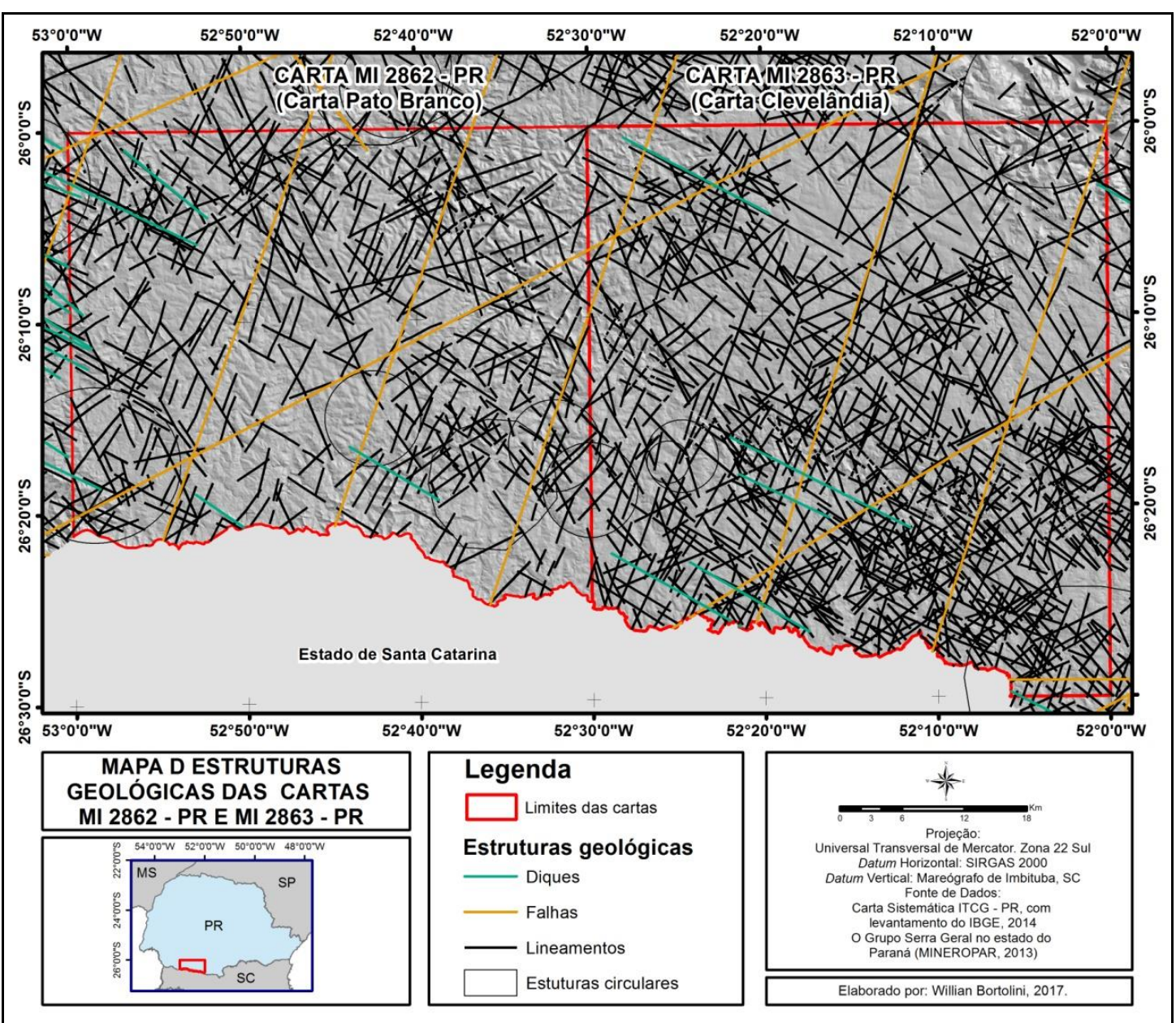

Figura 01 - Estruturas geológicas da área de estudo. Fonte: Adaptado de Mineropar (2013).

Em relação aos aspectos geomorfológicos (Figura 02), a área de estudo está inserida na unidade morfoestrutural (10 táxon) "Bacia Sedimentar do Paraná" e na unidade morfoescultural (2o táxon) "Terceiro Planalto Paranaense". Referentes ao 30 táxon, a área contempla as seguintes subunidades morfoesculturais (OKA-FIORI et al., 2006):

a) Planalto de Francisco Beltrão, ocupa área de 1769,18 km2 (38,69\%) das cartas, apresenta dissecação média, e as classes de declividade predominantes menores que $6 \%$, entre 6 e $12 \%$ e entre 12 e 30\%. Em relação ao relevo, apresenta um gradiente de 615 metros com altitudes variando entre 478 (mínima) m. s. n. m (metros sobre o nível do mar) e 1.093 (máxima) m. s. n. m., e as formas predominantes são topos alongados, vertentes convexas e vales em "V" aberto; b) Planalto de Palmas/Guarapuava, que ocupa uma área de 1828,94 km2 (40\%) das cartas, apresenta dissecação baixa, e as classes de declividades predominantes menores que $6 \%$. Em relação ao relevo, apresenta um gradiente de 471 metros com altitudes variando entre $680 \mathrm{~m}$. s. n. m. (mínima) e 1151 (máxima) m. s. n. m. (metros sobre o nível do mar), e as formas predominantes são topos aplainados, vertentes retilíneas e convexas e vales em " $U$ ";

c) Planalto do Alto Capanema, que ocupa uma área de 38,65 km2 (0,85\%) das cartas, apresenta dissecação alta, e a classe de declividade predominante entre 12 e 30\%. Em relação ao relevo, apresenta um gradiente de 352 metros com altitudes variando entre 637 m. s. n. m. (mínima) e 989 (máxima) m. s. n. m, e as formas predominantes são topos alongados e em cristas, vertentes retilíneas e vales em " $\mathrm{V}$ "; 


\section{EMPREGO DE TÉCNICAS GEOMORFOMÉTRICAS NA IDENTIFICAÇÃO DE PADRÕES DE RELEVO}

d) Planalto do Alto/Médio Piquiri, que ocupa uma área de 793,2 km2 (17,35\%) das cartas, apresenta dissecação média, e a classe de declividade predominante entre 12 e 30\%. Em relação ao relevo, apresenta um gradiente de 554 metros com altitudes variando entre 493 m. s. n. m. (mínima) e 1047 (máxima) m. s. n. m, e as formas predominantes são topos alongados e isolados, vertentes convexas e convexo-côncavas e vales em "U" aberto ;

e) Planalto de Clevelândia, que ocupa uma área de 61,91 km2 (1,35\%) das cartas, apresenta dissecação média, e as classes de declividades predominantes são menores que $6 \%$ e entre 12 e 30\%. Em relação ao relevo, apresenta um gradiente de 461 metros, com altitudes variando entre 673 m. s. n. m. (mínima) e 1.134 (máxima) m. s. n. $\mathrm{m}$, e as formas predominantes são topos aplainados com residuais de aplanação, vertentes convexas e convexo-côncavas e vales em " $V$ ";

f) Planalto do Foz do Areia/Ribeirão Claro, que ocupa uma área de 80,36 km2 (1,76\%), apresenta dissecação alta e a classe de declividade predominante é entre 12 e $30 \%$. Em relação ao relevo, apresenta um gradiente de 499 metros com altitudes variando entre 604 m. s. $n$. m. (mínima) e 1.103 (máxima) m. s. n. m, e as formas predominantes são topos alongados, vertentes retilíneas e côncavas e vales em degraus.

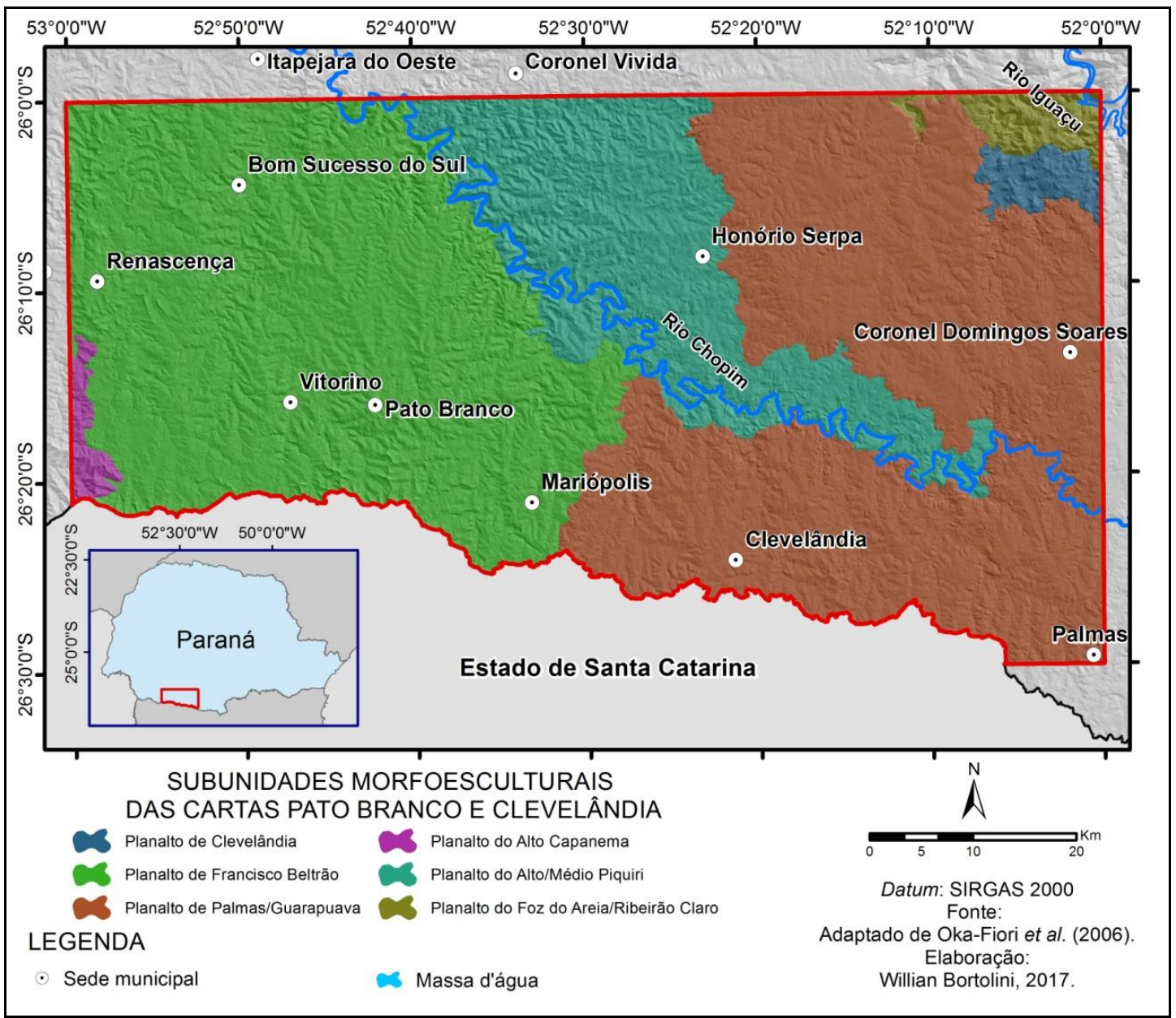

Figura 02 - Subunidades morfoesculturais da área de estudo. Fonte: Autores 


\section{EMPREGO DE TÉCNICAS GEOMORFOMÉTRICAS NA IDENTIFICAÇÃO DE PADRÕES DE RELEVO}

MATERIAIS E MÉTODOS

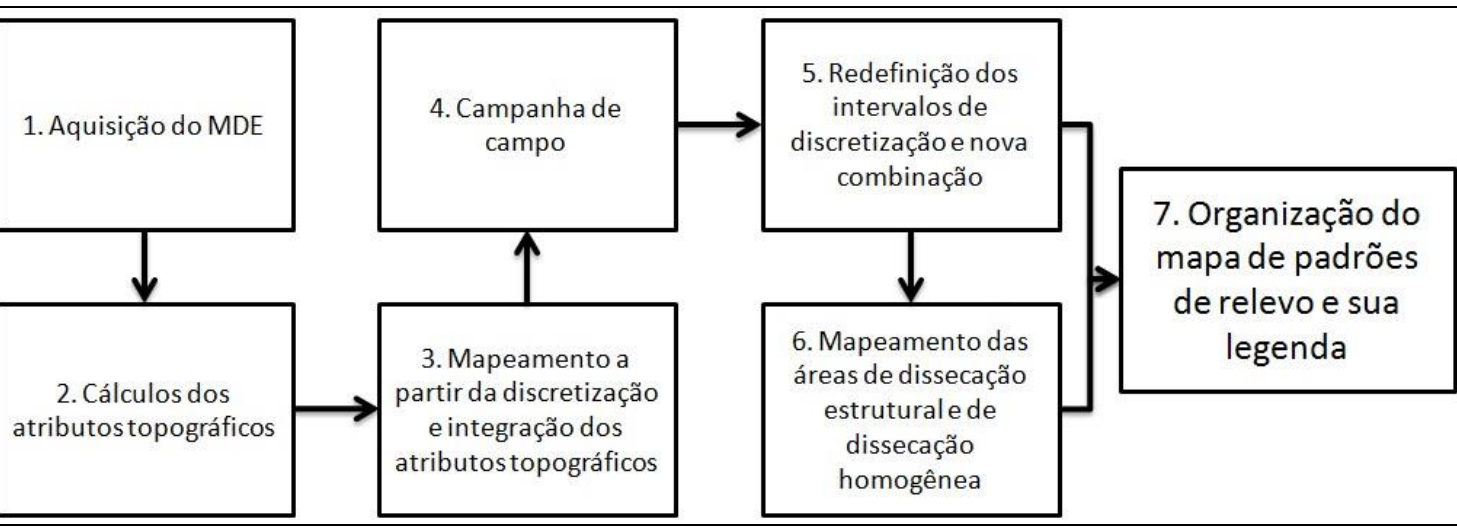

Figura 03 - Fluxograma das etapas metodológicas da pesquisa. Fonte: Autores.

Todos os processamentos foram realizados em ambiente de Sistemas de Informações Geográficas (SIG), utilizando o software ArcGIS 10.1 da ESRI (Environmental Systems Research Institute).

$\mathrm{Na}$ primeira etapa foram levantadas as bases de dados das Cartas Base do Departamento de Serviço Geográfico (DSG) do ano de 2002 e as Cartas Base do Instituto Brasileiro de Geografia e Estatística (IBGE), ambas na escala 1:50.000, contendo os dados de curvas de nível, ponto cotados e hidrografia; e o mapeamento geológico do Grupo Serra Geral do estado do Paraná realizado pela Mineropar (2013).

A partir dos dados vetoriais das curvas de nível, pontos cotados e hidrografia foi interpolado o MDE pelo método Topogrid (HUTCHINSON, 1988). A definição da resolução espacial (ou tamanho do pixel) foi baseada em dois diferentes métodos (HENGL, 2006): abordagem cartográfica (Equação 1) e complexidade do relevo (Equação 2). O primeiro calcula o tamanho do pixel em função do fator de escala da base de dados e o segundo calcula o tamanho do pixel em função da relação entre as curvas de nível e a área. O valor obtido pelo calculo do método de abordagem cartográfica resultou em uma resolução de 25 metros. Já o valor obtido pelo cálculo do método de complexidade do relevo resultou em uma resolução de 35 metros. Uma média entre os dois
A identificação de padrões de relevo por meio de técnicas geomorfométricas foi sistematizada em sete etapas (Figura 03): valores obtidos foi calculada, resultando em uma resolução espacial de 30 metros.

$p=S N \times 0,0005$

$\mathrm{p}=$ tamanho do pixel;

$\mathrm{SN}=$ fator de escala;

$$
p=\frac{A}{2 \times \Sigma l}
$$

$$
\begin{aligned}
& p=\text { tamanho do pixel; } \\
& A=\text { área; } \\
& \Sigma I=\text { soma do comprimento das curvas de }
\end{aligned}
$$

nível;

Em seguida, na segunda etapa, foram calculados os atributos topográficos, utilizados para identificar os padrões de relevo: amplitude altimétrica, declividade média e relevo sombreado. A amplitude altimétrica foi calculada a partir de um raio circular de 25 pixels $(750 \mathrm{~m})$. Este valor de raio foi determinado a partir de uma série de análises em perfis de vertentes (Figura 04), que demonstraram que o comprimento médio das vertentes da área de estudo é de aproximadamente $750 \mathrm{~m}$. A declividade foi inicialmente calculada a partir de uma janela móvel de $3 \times 3$ pixels. Em seguida, foi aplicado um cálculo de média com raio circular de 25 pixels $(750 \mathrm{~m})$, resultando no atributo média da declividade. 


\section{EMPREGO DE TÉCNICAS GEOMORFOMÉTRICAS NA IDENTIFICAÇÃO DE PADRÕES DE RELEVO}

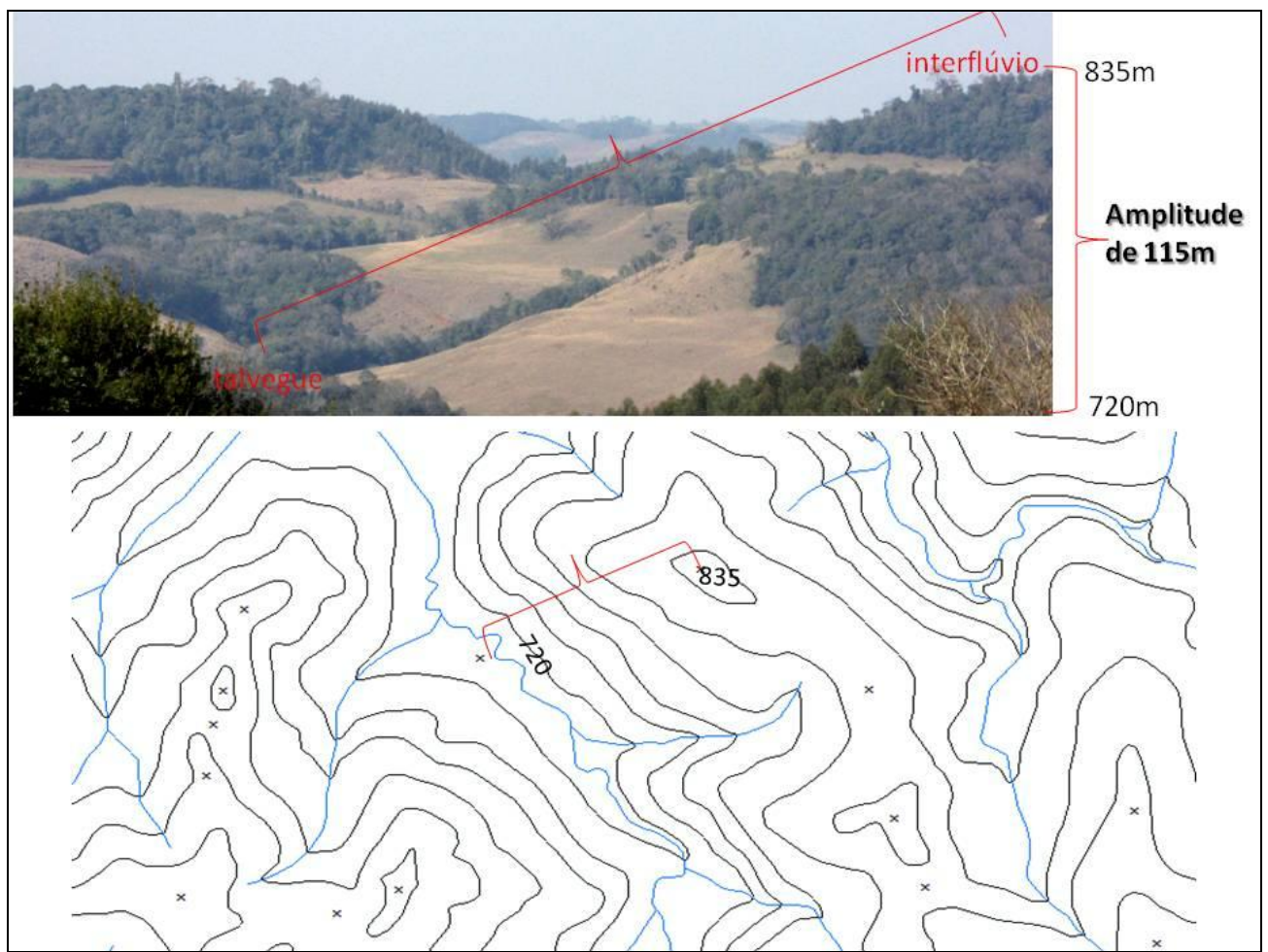

Figura 04 - Exemplo de vertente vista em perfil para avaliação do comprimento para a determinação do tamanho do raio. Fonte: Autores.

$\mathrm{Na}$ terceira etapa, os parâmetros de discretização dos atributos topográficos amplitude altimétrica e média da declividade foram definidos, respectivamente, conforme critérios determinísticos e parâmetros estatísticos. Para a segmentação, foram identificados seis distintos padrões de relevo (colinas, colinas onduladas, morrotes, morros, morros declivosos e serras), e os atributos topográficos amplitude altimétrica e média da declividade foram discretizados e combinados por meio de álgebra de mapas. O resultado preliminar obtido foi então submetido à validação em campo.
Na campanha de campo (quarta etapa), foram visitados e descritos 48 pontos (Figura 05) e suas respectivas características geomorfológicas, que serviram como amostras para a redefinição dos parâmetros (quinta etapa). Em laboratório identificou-se por meio do atributo topográfico relevo sombreado possíveis áreas pertencentes a cada padrão de relevo e delas foram identificadas e selecionadas mais amostras. 


\section{EMPREGO DE TÉCNICAS GEOMORFOMÉTRICAS NA IDENTIFICAÇÃO DE PADRÕES DE RELEVO}

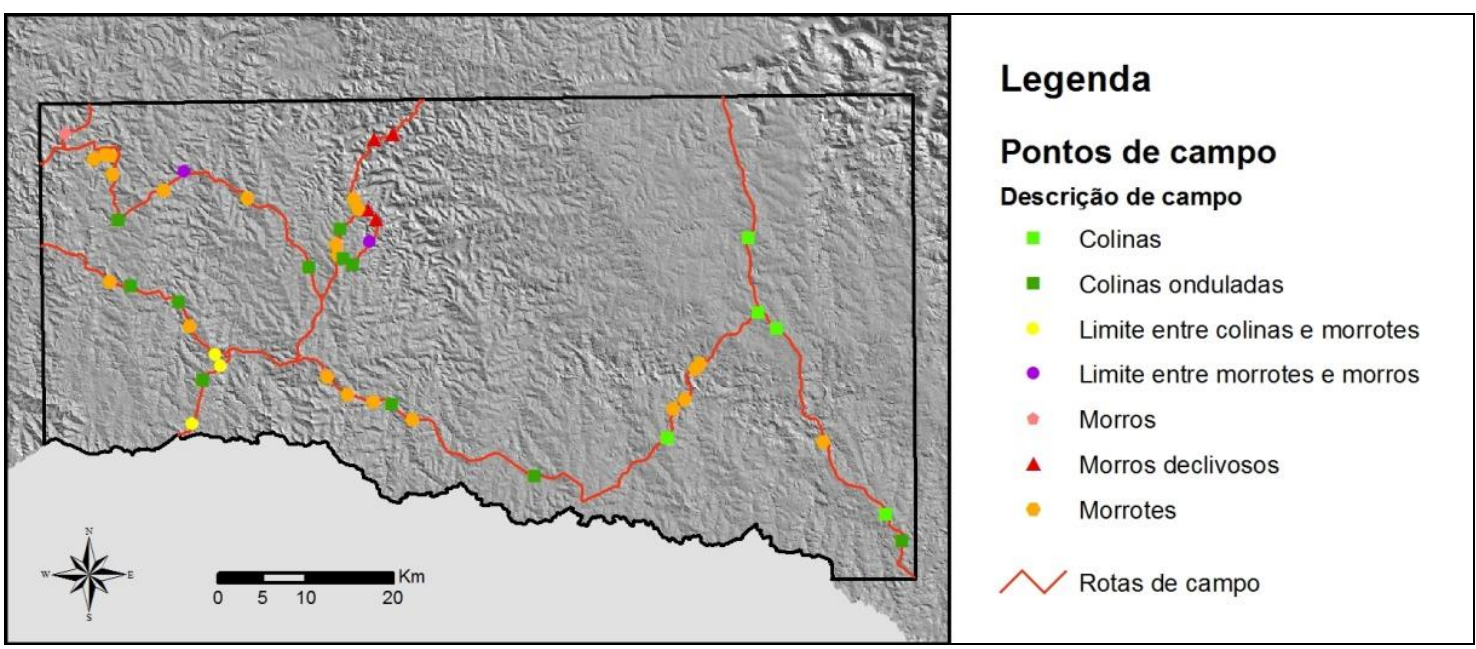

Figura 05 - Pontos e rotas percorridos na campanha de campo para a área de estudo. Fonte: Autores.

$\mathrm{Na}$ redefinição dos parâmetros, a amplitude altimétrica foi então discretizada em quatro classes (<80m; entre 80 e $120 \mathrm{~m}$; entre 120 e $240 \mathrm{~m}$; e $>240 \mathrm{~m}$ ), a partir do conhecimento das características da área de estudo obtidas pelos pontos amostrais visitados em campo ou identificados em laboratório. Já a média da declividade, por sua vez, foi discretizada em três classes, usando como base critérios estatísticos com os valores da média (12,3\%) e do desvio padrão (5,4\%): 1a Classe: < 1,5 desvio padrão abaixo da média; 2a classe: entre 1,5 desvio padrão abaixo da média e 1,5 desvio padrão acima da média; 3a classe: > 1,5 desvio padrão acima da média.

Os parâmetros de discretização dos atributos topográficos calculados são apresentados na Tabela 01.

Tabela 1 - Parâmetros de discretização dos atributos topográficos

\begin{tabular}{ccc}
\hline Padrão de relevo & Amplitude altimétrica (m) & Média da declividade (\%) \\
\hline Colinas & $<80$ & $<6,9$ \\
Colinas onduladas & $<80$ & $6,9-17,7$ \\
Morrotes & $<80$ & $>17,7$ \\
& $80-120$ & $<17,7$ \\
Morros & $80-120$ & $>17,7$ \\
& $120-240$ & $<17,7$ \\
Morros declivosos & $120-240$ & $>17,7$ \\
Serras & $>240$ & Qualquer \\
\hline
\end{tabular}

Os atributos topográficos foram então discretizados segundo os parâmetros estabelecidos. Na sequência a amplitude altimétrica e a declividade média foram combinadas por meio de álgebra de mapas, e em seguida classificadas segundo a combinação de parâmetros destacada na Figura 06, resultando no mapeamento dos padrões de relevo e suas respectivas tipologias. 


\section{EMPREGO DE TÉCNICAS GEOMORFOMÉTRICAS NA IDENTIFICAÇÃO DE PADRÕES DE RELEVO}

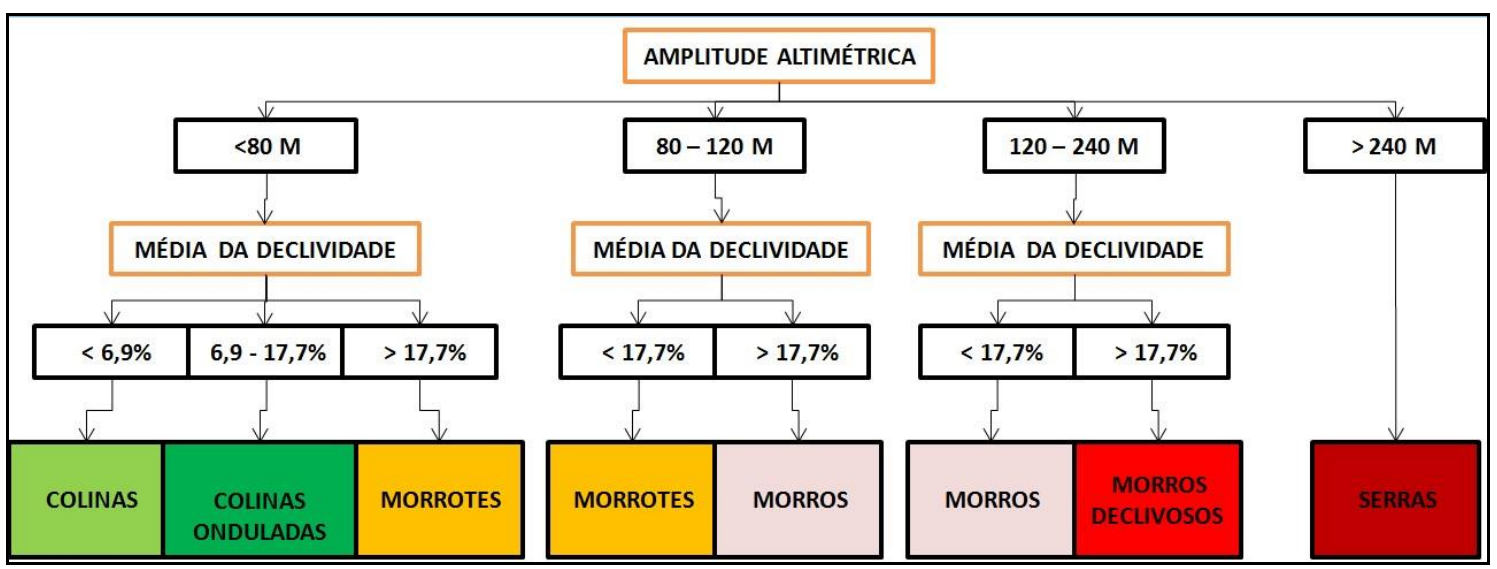

Figura 06 - Álgebra de mapas que resulta no mapeamento dos padrões de relevo. Fonte: Autores.

Na classificação resultante da álgebra de mapas foi aplicado um filtro de generalização que removeu agrupamentos de até 1963 pixels (ou $1767,15 \mathrm{~km} 2)$, que se refere a área do tamanho do raio circular aplicado ao cálculo dos atributos (750m). Este valor para a máscara foi determinado visando generalizar o mapeamento de uma maneira que porções com determinado padrão de relevo com área inferior à área do raio aplicado no cálculo dos atributos topográficos fossem suprimidas e classificadas como o padrão de relevo mais próximo.

$\mathrm{Na}$ sexta etapa foram identificadas as áreas que possuem feições de relevo controladas por estruturas geológicas, conferindo orientação de topos, cristas e vales. Este processo foi baseado na proposta do IBGE (2009). A identificação do controle linear estrutural geológico foi realizada a partir da interpretação da orientação de topos, cristas e vales detectados no relevo sombreado e sobrepostos às informações dos lineamentos estruturais de falhas, fraturas, diques e contatos litológicos mapeados pela Mineropar (2013). Para isto, foram delimitadas bacias hidrográficas de área inferior à área do tamanho do raio circular aplicado ao cálculo dos atributos, ou seja 1963 pixels (ou 1767,15 km2), e cada uma das bacias foi classificada de acordo com a existência ou não de controle estrutural das feições geomorfológicas.

Como sétima etapa, o mapa geomorfológico e sua legenda foram organizados, representando os padrões de relevo e seus respectivos processos de dissecação que o controlam.

Por fim, a partir da comparação entre os padrões de relevo mapeados com a realidade observada em campo, foram realizadas ajustes manuais entre os limites de alguns objetos modelados. Tratam-se de áreas de transição entre padrões de relevo em que o raio de análise de vizinhança extrapolou a abrupta mudança morfológica (diferenças do comprimento das vertentes no contato entre distintos padrões de relevo) e que, por esse motivo, apresentaram o limite em meio à vertente, necessitando de ajustes que demarcassem o limite no local onda há a mudança morfológica entre os padrões de relevo (Figura 07). 


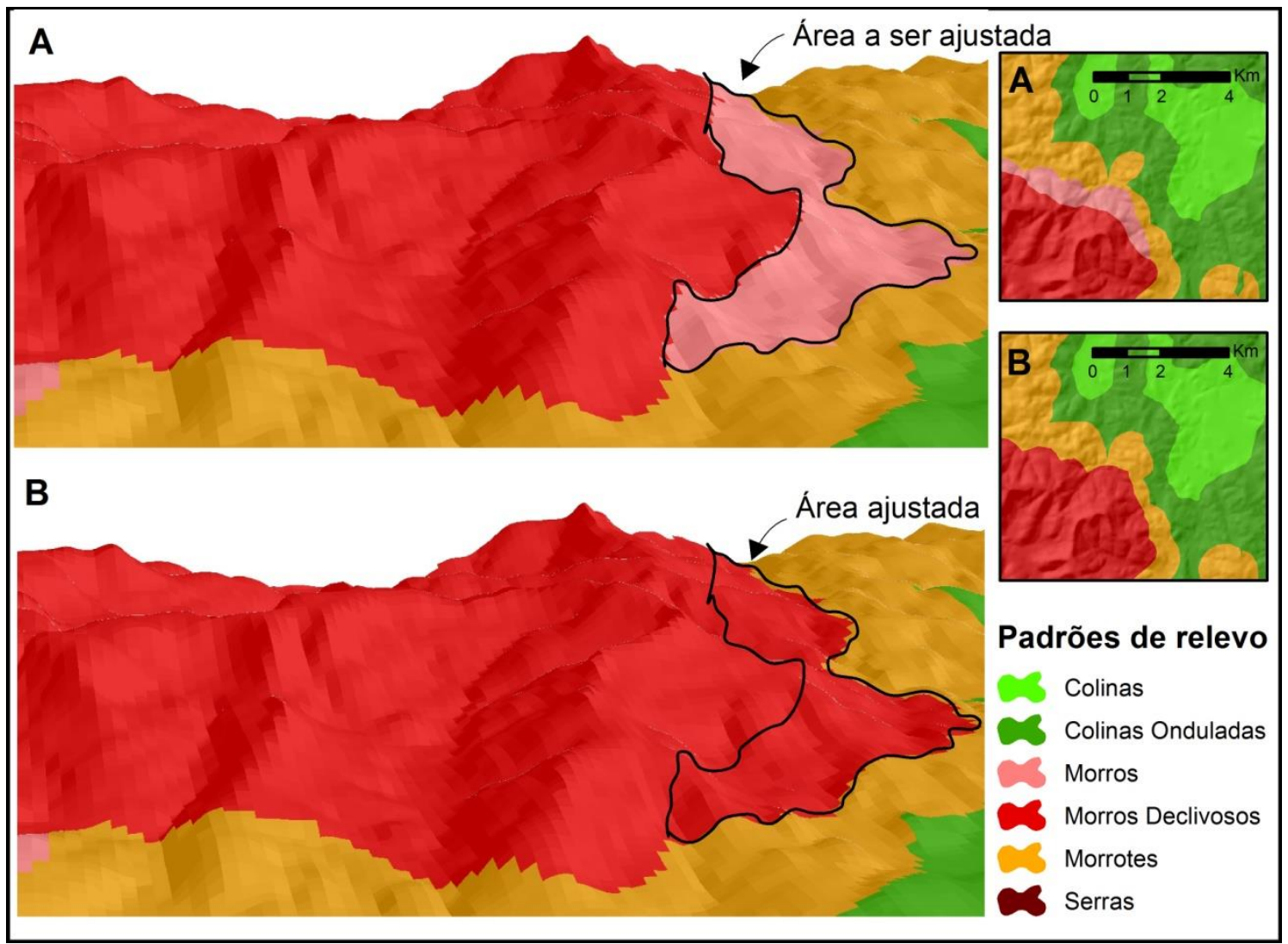

Figura 07 - Exemplo de limite entre padrões de relevo que necessitou de ajustes manuais. Fonte: Autores

\section{RESULTADOS E DISCUSSÕES}

Foram identificados e mapeados seis padrões de relevo no recorte estudado: colinas, colinas onduladas, morrotes, morros, morros declivosos e serras, sendo originados a partir de dois tipos de controle de dissecação: homogênea e estrutural. O mapa geomorfológico do 40 táxon para as cartas Pato Branco e Clevelândia é apresentado pela Figura 08. 


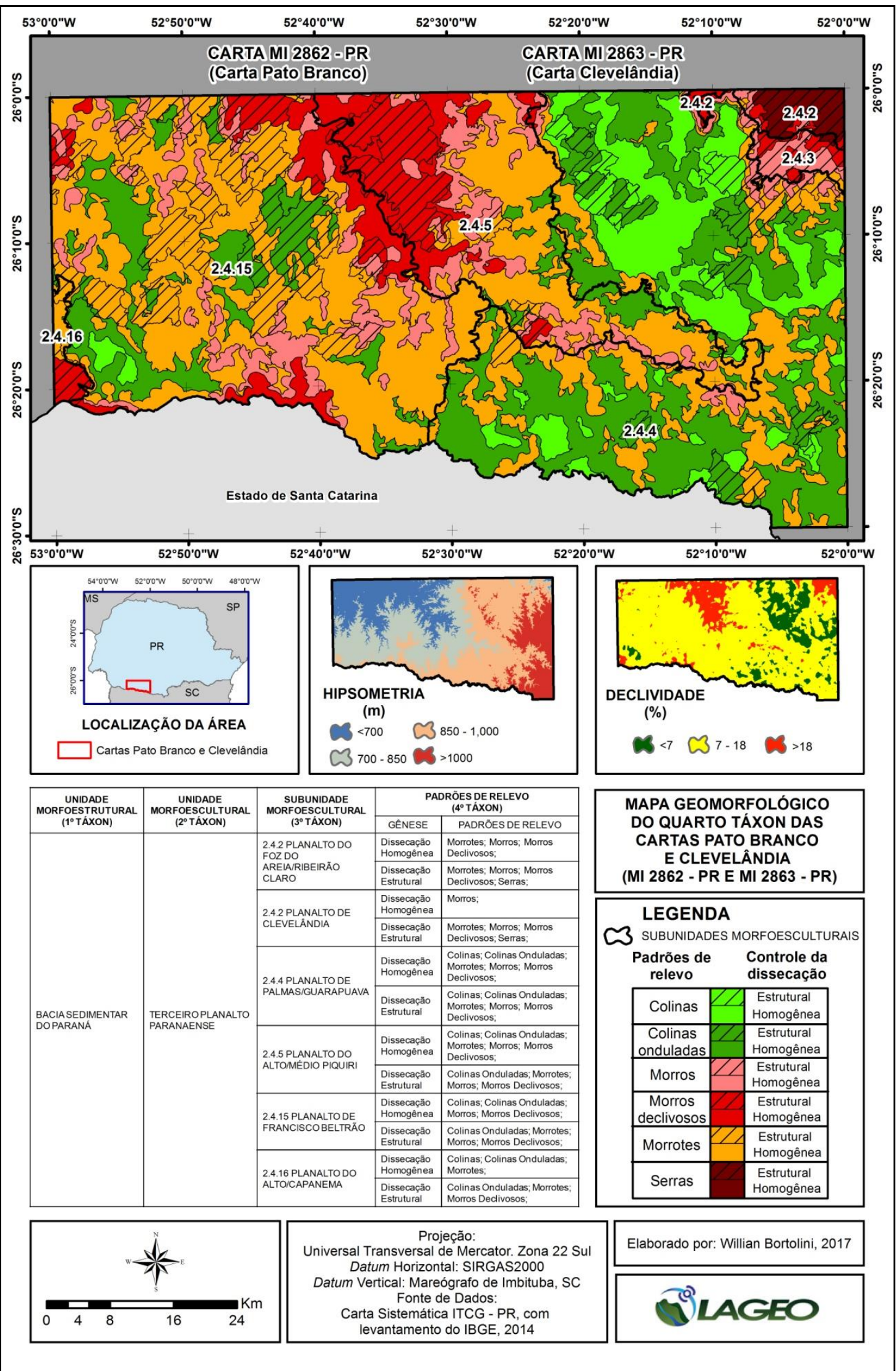

Figura 08 - Mapa geomorfológico no 4o táxon para as Cartas Pato Branco e Clevelândia (MI 2862 e MI 2863). Fonte: Autores. 


\section{EMPREGO DE TÉCNICAS GEOMORFOMÉTRICAS NA IDENTIFICAÇÃO DE PADRÕES DE RELEVO}

Os padrões de relevo identificados e mapeados são descritos da seguinte maneira:

1. Colinas (Figura 09A): caracterizam-se por possuírem vertentes médias ou longas (entre aproximadamente $500 \mathrm{~m}$ e $900 \mathrm{~m}$ ), vales abertos e pela forma levemente arredondada e com ondulação suave (declividade inferior à 6,9\%). Ocupam área de 491 km2 (10,73\% da área de estudo), sendo $13,74 \%$ com dissecação estrutural e 86,16\% com dissecação homogênea. Ocorrem, predominantemente, nas porções mais elevadas da área de estudo, chegando a 1144 metros de altitude na região de divisor de águas entre o rio Iguaçu e rio Chopim, com altitude média de 981 metros. A declividade média é de $5 \%$.

2. Colinas onduladas (Figura 09B): assemelham-se ao padrão de relevo de colinas, entretanto apresentam maior ondulação (declividade entre $6,9 \%$ e $17,7 \%$ ) na forma. Ocupam área de $1254,4 \mathrm{~km} 2$ (27,43\% da área de estudo), sendo $83,1 \%$ com dissecação homogênea e 16,9\% com dissecação estrutural. Apresentam-se nas porções mais altas do relevo, próximas às partes altas do rio Chopim, assumindo altitudes de até 1150 metros, além de algumas áreas a leste do mesmo rio. Possui altitude média de 903 metros e declividade média de $8 \%$.

3. Morrotes (Figura 09C): caracterizamse como um padrão de relevo com características intermediárias entre colinas onduladas e morros. Apresentam vertentes médias ou longas (entre aproximadamente $500 \mathrm{~m}$ e $100 \mathrm{~m}$ ) e vales abertos (semelhantes às colinas onduladas), entretanto possuem topos declivosos (declividade acima de $17.7 \%$ ) e arredondados, se assemelhando com pequenos morros. Ocupam área de $1782,33 \mathrm{~km} 2$ (38,99\% da área de estudo), sendo $22,65 \% \mathrm{com}$ dissecação estrutural e 77,35\% dissecação homogênea. Este é o padrão de relevo com maior área do relevo, abrangendo desde as porções mais baixas, inferiores a 500 metros, até porções mais elevadas, superiores a 1100 metros de altitude, próximas às áreas mais altas do rio Chopim. Possuem altitude média de 802 metros e declividade média de $12 \%$.
4. Morros (Figura 09D): caracterizam-se por possuírem declividade média (entre 6,9\% e $17,7 \%)$, vales fechados e vertentes curtas ou médias (entre aproximadamente $300 \mathrm{~m}$ e $700 \mathrm{~m}$ ), por isso caracterizando-se como um relevo com dissecação evoluída e, diferentemente dos morrotes, não possuem áreas com forma semelhante às colinas onduladas (que servem como "base" para os topos) e possuem geralmente maior amplitude altimétrica local (entre 120 e 240 metros). Ocupam área de $500,51 \mathrm{~km} 2$ (10,95\% da área de estudo), sendo desta 72,37\% com dissecação homogênea e $27,63 \%$ relacionada a dissecação estrutural. Localizam-se, majoritariamente, em áreas próximas ao rio Chopim e ao rio Iguaçu, além de áreas próximas ao limite entre os estados do Paraná e Santa Catarina, quase sempre circundando áreas de maior dissecação, configurando áreas de transição entre os padrões de relevo de morrotes e morros declivosos. Apresentam as maiores altitudes nas porções mais a montante do rio Chopim e nas porções próximas ao rio Iguaçu, atingindo altitudes superiores a 1000 metros, e as altitudes menores são observadas nas porções mais a jusante do rio Chopim. A altitude média é de 779 metros e a declividade média é de $15 \%$.

5. Morros declivosos (Figura 09E): possuem formas semelhantes ao padrão de morros, entretanto, apresentam declividades mais acentuadas (acima de $17,7 \%$ ) e vertentes curtas, médias ou longas (entre $400 \mathrm{~m}$ e $900 \mathrm{~m}$ ), o que resulta em um padrão de relevo com alto grau de dissecação. Ocupam área de 488,45 km2 (10,68\% da área de estudo), sendo desta 47,6\% com dissecação homogênea e 52,4\% com dissecação estrutural. Localizam-se, majoritariamente, nas áreas menos elevadas próximas ao rio Chopim, atingindo altitudes inferiores a 500 metros, além de porções próximas ao rio Iguaçu e no limite do estado, onde apresenta altitudes mais elevadas, chegando a ultrapassar 1000 metros. A altitude média é de 692 metros e a declividade média é de $21 \%$. 


\section{EMPREGO DE TÉCNICAS GEOMORFOMÉTRICAS NA IDENTIFICAÇÃO DE PADRÕES DE RELEVO}

6. Serras: apresentam grande amplitude altimétrica local (>240m) e declividades acentuadas (>17.7\%). Suas vertentes são médias ou longas (entre aproximadamente $600 \mathrm{~m}$ e 1000 $\mathrm{m})$ e seus vales são muito entalhados. Ocupam área de 55,16 km2 (1,2\% da área de estudo), com dissecação submetida ao controle estrutural.
Localiza-se em uma única porção da área de estudo, próxima ao rio Iguaçu, assumindo altitudes até superiores a 1000 metros. A altitude média é de 825 metros e a declividade média é de $29 \%$. 


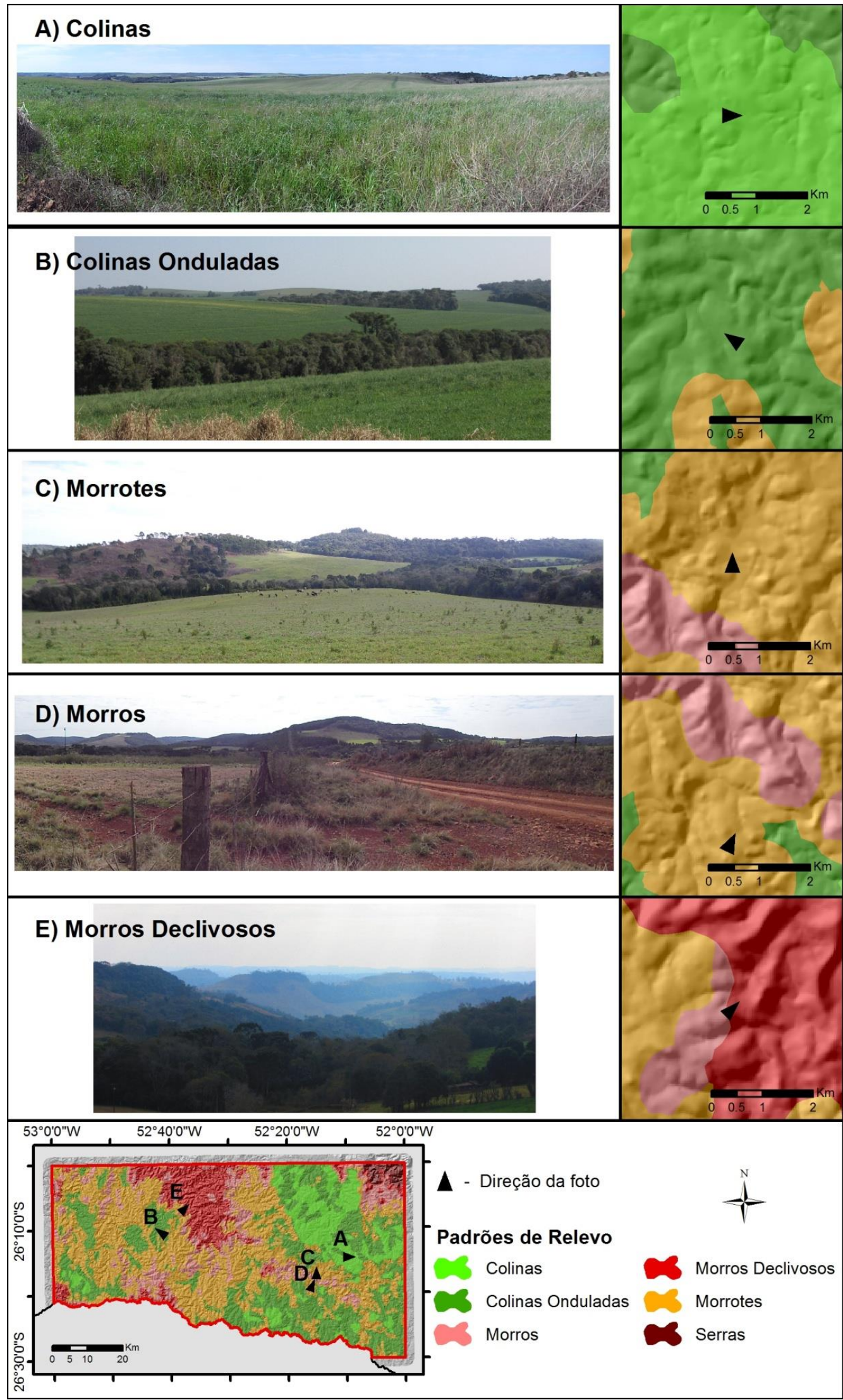

Figura 09 - Padrões de relevo identificados e mapeados. Fonte: Autores. 


\section{EMPREGO DE TÉCNICAS GEOMORFOMÉTRICAS NA IDENTIFICAÇÃO DE PADRÕES DE RELEVO}

Destaca-se que devido às limitações de escala do mapa resultante não foi possível representar as planícies fluviais, já que a extensão dessas feições na área de estudo não contempla a área mínima mapeável preestabelecida. Sua ocorrência, portanto, está condicionada a abordagens mais detalhadas.

Os tipos de controle de dissecação identificados para os padrões de relevo na área foram:

1. Dissecação homogênea: se caracteriza pela ação fluvial em litologias diversas que não apresentam controle estrutural marcante. Neste tipo de controle de dissecação observa-se diversos tipos de padrões de drenagem, porém com predomínio de padrão dendrítico, secundariamente subparalelo, subretangular e outros compostos, cujos canais não seguem uma direção preferencial.

2. Dissecação estrutural: é marcada por evidente controle estrutural, em rochas deformadas, caracterizada por inúmeras cristas, vales e sulcos estruturais. Os padrões de drenagem treliça, paralelo e retangular indicam possíveis estruturas geológicas ou acamamento estratigráfico.

Analisando a distribuição espacial dos padrões de relevo, percebeu-se que as áreas caracterizadas como padrões de relevo de maior grau de dissecação (amplitude altimétrica acima de 120 metros e média da declividade acima de $17,7 \%$ ), como os morros declivosos e as serras, se localizam próximas aos dois principais níveis de base fluvial presentes na região, os rios Chopim e Iguaçu, e em contrapartida as áreas caracterizadas como padrões de relevo de baixo grau de dissecação (amplitude altimétrica abaixo de 120 metros e média da declividade abaixo de $17,7 \%)$ estão localizados majoritariamente em áreas de maior altitude, nas posições de montante, mais distantes do nível de base fluvial. Isso evidencia a ação dos processos denudacionais como agentes da modificação do relevo local. A exceção neste contexto são os por conta da porção de morros declivosos localizados no limite entre os estados do Paraná e Santa Catarina, que também se caracteriza como divisor de águas entre a bacia hidrográfico do rio Paraná e a bacia hidrográfico do rio Uruguai.

Outra característica de destaque observada na área estudada foi a relação entre o grau de dissecação do padrão de relevo com a porcentagem de sua área que possui forte controle dos lineamentos estruturais. Observouse que os padrões de relevo serras e morros declivosos apresentam maior porcentagem de área de dissecação com controle estrutural (100\% e 52\%, respectivamente), enquanto os padrões de relevo colinas e colinas onduladas predominam áreas de dissecação homogênea (86\% e $83 \%$ respectivamente). Isto demonstra que a presença de estruturas geológicas, falhas, fraturas, e demais lineamentos, promovem o encaixe da rede de drenagem às estruturas e por consequência o aprofundamento do talvegue, controlados também pelo nível de base fluvial dos principais rios, refletindo no controle denudacional com mais energia e resulta em padrões de relevo com alto grau de dissecação na área estudada.

Conforme citado anteriormente, alguns limites entre padrões de relevo mapeados necessitaram de ajustes manuais, a partir de interpretação visual do relevo sombreado. Estas áreas totalizaram $0,77 \%$ de área total do recorte estudado. 0 padrão de relevo Serras foi o que obteve a menor concordância (84\%) na comparação entre o mapeamento sem ajustes manuais e o mapeamento com ajustes manuais, evidenciando a maior necessidade de ajustes e menor precisão do mapeamento digital aplicado. O padrão de relevo Morros obteve a segunda menor concordância $(96,3 \%)$ e o padrão de relevo Morros Declivosos a terceira menor concordância (98,4\%). Os demais padrões obtiveram concordância acima de $99 \%$.

A razão para as imperfeições nos limites entre os padrões se deve ao tamanho do raio utilizado para o cálculo dos atributos topográficos utilizados. Este raio, relativamente grande, tende a trazer imprecisões nos limites de áreas que possuem vertentes de comprimentos superiores ao seu tamanho (tanto para vertentes longas quanto curtas), pois o mesmo busca abranger de 


\section{EMPREGO DE TÉCNICAS GEOMORFOMÉTRICAS NA IDENTIFICAÇÃO DE PADRÕES DE RELEVO}

forma coerente as vertentes de tamanho intermediário, que são mais frequentes nas áreas de estudo. Isto é evidenciado pelo fato que os padrões que necessitaram de maiores ajustes foram os que possuem presença de feições com vertentes curtas (como morros e morros declivosos) ou maior presença de feições com vertentes longas (como na área de serras e alguns pontos de morros declivosos). Outras considerações a serem acrescidas se referem ao fato de que em padrões de relevo que apresentam vertentes alongadas, grande gradiante altimétrico local e tem seu limites marcados por uma ruptura hipsométrica abrupta, a modelagem digital aplicada não permite discriminar com precisão tais rupturas, resultando em um compartimento impreciso das vertentes, classificando as porções mais baixas como padrões de relevo menos dissecados, até as porções mais altas que ficaram classificadas como padrões de relevo mais dissecados (Figura $10 \mathrm{~A}, 10 \mathrm{~B}$ e $10 \mathrm{C})$.

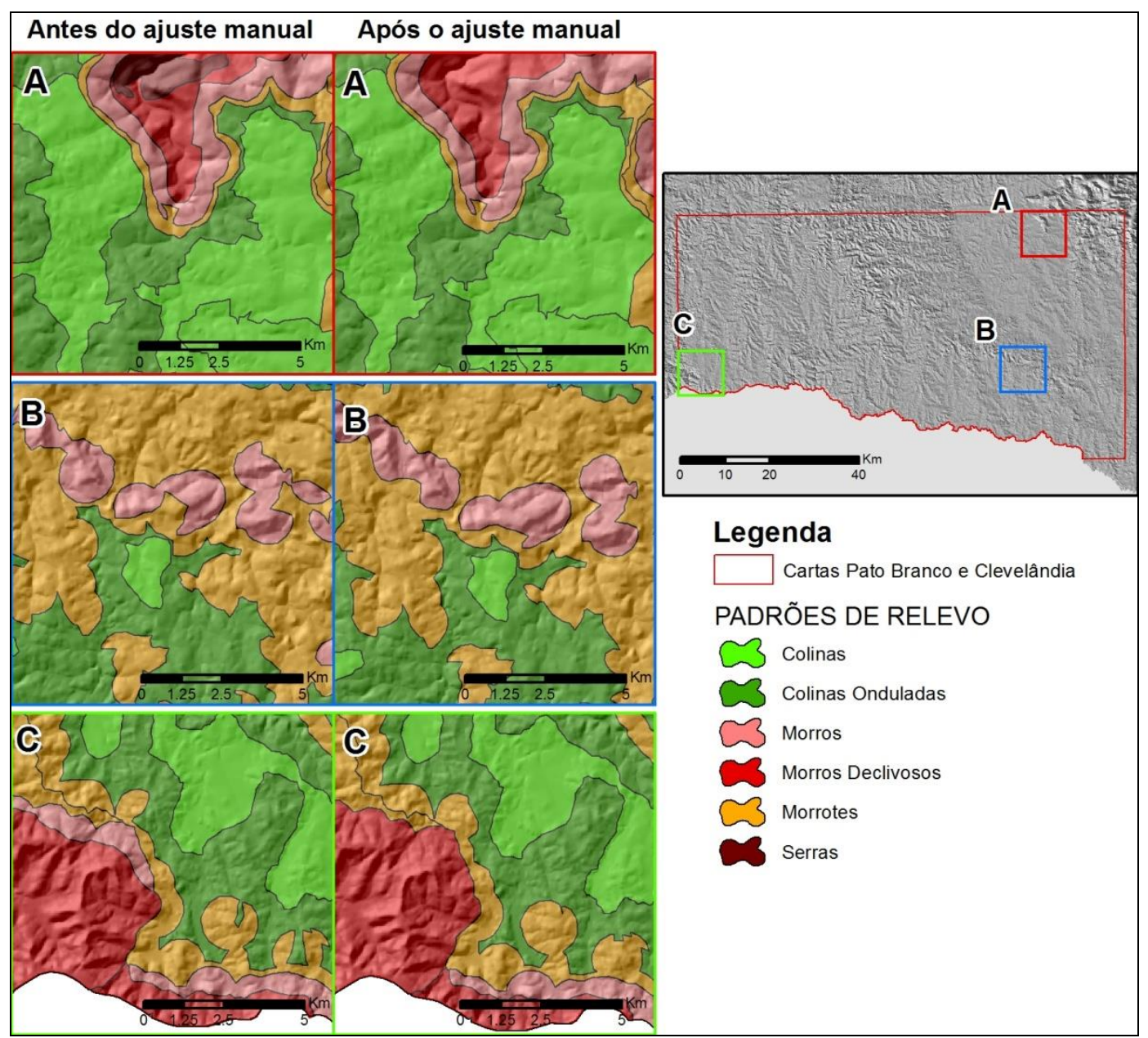

Figura 10 - Recortes de áreas que sofreram ajustes manuais nos limites entre padrões de relevo. Fonte: Autores.

Sobrepondo o mapa de padrões de relevo final, já ajustado manualmente, com a localização dos 48 pontos levantados em campo (Figura 05), observou-se que em apenas cinco destes pontos ( $8,3 \%$ dos pontos) a descrição de campo não condiz com o que foi mapeado. Esta discordância deve-se ao fato de que em campo observa-se apenas uma porção limitada do relevo, que pode assumir naquele exato ponto características diferentes do relevo que predomina em seu entorno. Como o que se busca mapear neste trabalho são padrões de relevo, que representam as características geomorfológicas predominantes em uma 


\section{EMPREGO DE TÉCNICAS GEOMORFOMÉTRICAS NA IDENTIFICAÇÃO DE PADRÕES DE RELEVO}

determinada área, estas porções isoladas de pequena abrangência e características distintas acabam sendo suprimidas e incorporadas pelo padrão de relevo mais próximo a partir do uso de um raio grande para o cálculo dos atributos e pelo processo de generalização.

\section{CONCLUSÕES}

A área de estudo mapeada caracterizase pela predominância de padrões de relevo de baixo ou médio grau de dissecação $(77,15 \%$ da área), sendo estes colinas, colinas onduladas e morrotes. As áreas de padrões de relevo de alto grau de dissecação concentraram-se nas áreas próximas as porções mais baixas dos principais rios do recorte. As demais áreas localizaram-se em áreas de interflúvio e áreas elevadas, evidenciando um processo de dissecação baseado na ação fluvial. As áreas de relevo formado por processos de dissecação com influência estrutural localizam-se majoritariamente nas porções mais dissecadas, indicando uma relação entre a influência dos lineamentos geológicos estruturais e a ação dos processos denudacionais.

Quanto ao método de mapeamento digital aplicado neste trabalho, demonstrou-se válido e possibilitou a identificação dos padrões de relevo, assim oferece um modo eficiente para mapeamento geomorfológico atendendo às proposição hierárquicas do quarto táxon. A afirmativa conclusiva está amparada na elevada concordância entre os resultados obtidos por meio das regras de classificação e as observações em campo.

A principal observação a ser destacada sobre este método é a atenção que se deve tomar no momento da decisão do tamanho do raio a ser utilizado no cálculo dos atributos topográficos, que deve sempre abranger o comprimento médio predominante nas vertentes da área de estudo.

As limitações apresentadas pelo método dizem respeito à dificuldade do mapeamento de porções que apresentam vertentes com comprimento extremante longos ou curtos, trazendo imprecisões nos limites entre padrões de relevo e até mesmo compartimentando vertentes longas em mais de um padrão de relevo. A forma encontrada para sanar estas limitações foi realização de ajustes manuais. Apesar destas limitações, este método semiautomatizado de mapeamento de padrões de relevo se mostrou capaz de atender ao nível de representação estabelecido na geomorfológica.

\section{AGRADECIMENTOS}

Os autores agradecem ao Conselho Nacional de Desenvolvimento Científico e Tecnológico (CNPq) pela disponibilização de recursos por meio do Projeto de Mapeamento do Estado do Paraná apoiado em análise digital do relevo, Processo 456244/2014-0; à Fundação Araucária pela disponibilização de bolsa de iniciação científica por meio da PRPPG/UFPR e ao Laboratório de Pesquisas Aplicadas em Geomorfologia e Geotecnologias (LAGEODEGEOG-UFPR)

\section{REFERÊNCIAS}

AUGUSTIN, C. H. R.; FONSECA, B. M.; ROCHA, L. C. Mapeamento geomorfológico da Serra do Espinhaço Meridional: primeira aproximação. Geonomos. Ano 19. n. 2. p. 50 - 69. 2011.

CASSETI, V. Geomorfologia. [S.I.]: [2005]. Disponível em: < http://www.funape.org.br/geomorfologia/> . Acesso em 29 de outubro 2016.

CARNEIRO, C. D. ; SOUZA, J. J. Mapeamento geomorfológico em escala de semidetalhe da região de Jundiaí - Atibaia. Revista Brasileira de Geomorfologia. Ano 4, n. 2. p. 17-30. 2003.

COLTRINARI, L. Cartografia geomorfológica detalhada: a representação gráfica do relevo entre 1950-1970. Revista Brasileira de Geomorfologia. v.12, n.3, p.121-130, 2011.

CPRM - SERVIÇO GEOLÓGICO DO BRASIL; IPT INSTITUTO DE PESQUISAS TECNOLÓGICAS. Cartas de suscetibilidade a movimentos gravitacionais de massa e inundações - 1:25.000. Ed. 1 (Nota técnica explicativa). Serviço Geológico do Brasil; Instituto de Pesquisas Tecnológicas. São Paulo, 2014. 


\section{EMPREGO DE TÉCNICAS GEOMORFOMÉTRICAS NA IDENTIFICAÇÃO DE PADRÕES DE RELEVO}

DIKAU, R. The application of a digital relief model to landform analysis. In: RAPER, J. F. (Ed.), Three Dimensional Applications in Geographical Information Systems. Taylor \& Francis, London, pp. 51-77, 1989.

DIKAU, R.; BRABB, E. E.; MARK, R. M. Landform Classification of New Mexico by Computer. Open File report 91-634. U.S. Geological Survey, 1991.

GERASSIMOV, I. P.; MESCHERIKOV, J. L. Morphostructure. In: FAIRBRIDGE, R. W. (Ed.). The encyclopedia of geomorphology. New York: Reinhold Book Corp., 1968.

HENGL, T. Finding the right pixel size. Computers \& Geosciences. 32, 1283-1298, 2006.

HENGL, T.; REUTER, H. I. (eds.) Geomorphometry: Concepts, Software, Applications. Series Developments in Soil Science vol. 33, Amsterdam: Elsevier, pp. 31-64, 2009.

HENGL, T; MCMILLAN, R. A. Geomorphometry: A Key to Landscape Map and Modelling. In: HENGL, T.; REUTER, H. I. (eds.) Geomorphometry Concepts, Software, Applications, Series Developments in Soil Science vol. 33, Amsterdam: Elsevier, pp. 433-460, 2009.

HUTCHINSON, M. F. Calculation of hydrologically sound digital elevation models. Paper presented at Third International Symposium on Spatial Data Handling at Sydney, Australia, 1988.

IBGE - INSTITUTO BRASILEIRO DE GEOGRAFIA E ESTATÍSTICA. Manual Técnico de Geomorfologia. 2 ed. Rio de Janeiro, 2009.

IWAHASHI, J. ; PIKE, R. J. Automated classification of topography from DEMs by an unsupervised nested-means algorithm and a three-part geometric signature. Geomorphology. 86, 409440, 2007.

MESCERJAKOV, J. P. Les concepts de morphostruture et de morphosculture: un nouvel instrument de l'analyse géomorphologique. Annales de Géographie, Paris, t. 77, n. 423, p. 539-552, 1968.

MILANI, E. J.; FACCINI, U. F.; SHERER, C. M.; ARAÚJO, L. M.; CUPERTINO, J. A. Sequences and stratigraphic hierarchy of the Paraná Basin (Ordoviciano Cretaceous), Southern Brazil. Bol. IG USP, Série Científica no 29, p. 125-173, 1998.

MINÁR, J.; EVANS, I. S. Elementary forms for land surface segmentation: the theoretical basis of terrain analysis and geomorphological mapping. Geomorphology 95 (3-4), 236-259, 2008.

MINEROPAR - SERVIÇO GEOLÓGICO DO PARANÁ. Atlas geológico do estado Paraná. Minerais do Paraná, Curitiba, 2001.

MINEROPAR - SERVIÇO GEOLÓGICO DO PARANÁ. O Grupo Serra Geral no estado do Paraná: mapeamento geológico das cartas 1:250.000 de Guaíra, Guaraniaçu, Cascavel, Campo Mourão, Guarapuava, Pato Branco e Clevelândia. Vol 1 (Textos). Minerais do Paraná. Curitiba, 2013.

MINEROPAR - SERVIÇO GEOLÓGICO DO PARANÁ. O Grupo Serra Geral no estado do Paraná: mapeamento geológico das cartas 1:250.000 de Guaíra, Guaraniaçu, Cascavel, Campo Mourão, Guarapuava, Pato Branco e Clevelândia. Vol 2 (Anexos). Minérios do Paraná. Curitiba, 2013.

OKA-FIORI, C., SANTOS, L.J.C., CANALI, N.E., FIORI, A.P., SILVEIRA, C.T., SILVA, J.M.F., ROSS, J.L.S. Atlas geomorfológico do estado do Paraná: Escala base 1:250.000 modelos reduzidos. Minerais do Paraná; Universidade Federal do Paraná. Curitiba, 2006.

PIKE, R. J.; EVANS, I., HENGL, T. Geomorphometry: A Brief Guide. In: HENGL, T.; REUTER, H. I. (eds.) Geomorphometry - Concepts, Software, Applications, Series Developments in Soil Science vol. 33, Amsterdam: Elsevier, pp. 330, 2009.

PONÇANO, W. L. (Coord.) et al. Mapa geomorfológico do Estado de São Paulo. São Paulo: IPT, 1981. 2 v. (Publicação IPT, 1 183; Monografias, 5).

ROBAINA, L.E.S; TRENTIN, R.; LAURENT, F. Compartimentação do estado do Rio Grande do Sul, Brasil, através do uso de geomorphons obtidos em classificação topográfica automatizada. Revista Brasileira de Geomorfologia, São Paulo, v.17, n.2, p.287-298, 2016.

ROSS, J. L. S. Geomorofologia, Ambiente e Planejamento. S. Paulo, Ed. Contexto.1990.

ROSS, J. S.; MOROZ, I.C. Mapa geomorfológico do estado de São Paulo. São Paulo: Laboratório de Geomorfologia Depto de Geografia FFLCHUSP/Laboratório de Cartografia Geotécnica - Geologia Aplicada - IPT/FAPESP, 1997.

ROSS, J. S. Registro cartográfico dos fatos geomorfológicos e a questão da taxonomia do relevo. Rev. Geografia. São Paulo, IG-USP, 1992. 


\section{EMPREGO DE TÉCNICAS GEOMORFOMÉTRICAS NA IDENTIFICAÇÃO DE PADRÕES DE RELEVO}

SAMPAIO, T.V.M. AUGUSTIN, C.H.R.R. Índice de Concentração da Rugosidade: uma nova proposta metodológica para o mapeamento e quantificação da dissecação do relevo como subsídio a cartografia geomorfológica. Revista Brasileira de Geomorfologia. v. 15, n. 1, p. 47-60, 2014.

SANTOS, L. J. C. et al. Mapeamento Geomorfológico do Estado do Paraná. Revista Brasileira de Geomorfologia. Ano 7, n. 2. p. 03-11. 2006

SILVA, J. M. F. Caracterização e mapeamento das unidades geomorfológicas da bacia do rio Pequeno, Antonina - PR. 2010. 93 f. Dissertação (Mestrado em Geografia). Departamento de Geografia, Universidade Federal do Paraná, Curitiba. 2010.

SILVEIRA, R. M. P. Análise digital do relevo como apoio para a cartografia geomorfológica da porção central da Serra do Mar Paranaense. 2015. 123 f. Dissertação (Mestrado em Geografia). Departamento de Geografia, Universidade Federal do Paraná, Curitiba. 2015.

SILVEIRA, R. M. P.; SILVEIRA, C. T. ; OKA-FIORI, C. Análise digital do relevo aplicada no mapeamento de unidades geomorfológicas. Revista Geografar, Curitiba, v. 7, n. 2, p. 43-68, 2012.

SILVEIRA, R. M. P.; SILVEIRA, C. T. ; OKA-FIORI, C. Emprego de técnicas de inferência espacial para identificação de unidades de relevo apoiado em atributos topográficos e árvore de decisão. Revista Brasileira de Geomorfologia, v.15, n.1, (Jan-Mar) p.87-101, 2014.

SILVEIRA, R. M. P.; SILVEIRA, C. T. Classificação hierárquica automatizada de formas do relevo no estado do Paraná apoiada na modelagem digital do terreno. Revista Brasileira de Geografia Física, v. 08 n. 05, p. 1509-1523, 2015.

SILVEIRA, R. M. P.; SILVEIRA, C. T. Análise digital do relevo aplicada à cartografia geomorfológica da porção central da Serra do Mar Paranaense. Revista Brasileira de Geomorfologia, São Paulo, v. 17, no 4, 615-629, 2016.

SMITH, M. J.; PARON, P.; GRIFFITHS, J. (eds.) Geomorphological Mapping: Methods and Applications. Developments in Earth Surface Processes vol 15, Elsevier, 2011.

SOUZA, L. F.; SAMPAIO, T. V. M. Aplicação do Índice de Concentração da Rugosidade à identificação de classes de dissecação do relevo: uma proposta de quantificação e automatização em ambiente SIG. III Simpósio Brasileiro de Ciências Geodésicas e Tecnologias da Geoinformação Recife -PE, 2010.

TRENTIN, R.; ROBAINA, L. E. S.; SILVEIRA, C. T. Compartimentação geomorfométrica da bacia hidrográfico do rio Itú/RS. Revista Brasileira de Geomorfologia. v. 16, no 2, p. 219-237, 2015.

TINÓS, T.M.; FERREIRA, V.V.; RIEDEL, P.S.; ZAINE, J.E. Aplicação e avaliação de metodologia de classificação automática de padrões de formas semelhantes do relevo. Revista Brasileira de Geomorfologia, São Paulo, v.15, n.3, p.353-370, 2014.

TOBLER, W. R. The development of analytical cartography - a personal note. Cartography and Geographic Information Science 27 (3), 189-194, 2000 .

VASCONCELOS. V.; CARVALHO JÚNIOR, O. A.; MARTINS, E. S. COUTO JUNIOR, A. F.; GUIMARÃES, R. F.; GOMES, R. A. T. Sistema de classificação geomorfométrica baseado em uma arquitetura sequencial em duas etapas: árvore de decisão e classificador espectral, no Parque Nacional Serra da Canastra. Revista Brasileira de Geomorfologia, v. 13, n. 2, p. 171-186, 2012.

WEISS, A. Topographic Position and Landforms Analysis. Poster presentation, ESRI User Conference, San Diego, CA, 2001.

WILSON, J. P.; GALLANT, J. C. (eds.). Terrain analysis: principles and applications. New York: John Wiley \& Sons, p.1-27, 2000.

WOOD, J. The geomorphological characterisation of digital elevation models. Leicester, UK, 1996. 185p. PhD Thesis - University of Leicester. Disponível em: http://www.soi.city.ac.uk/ jwo/phd.

ZALÁN, P. V.; WOLFF, S.; CONCEIÇÃO, J. C. J.; ASTOLFI, M. A. M.; VIEIRA, I. S.; APPI, V. L.; ZANOTTO, O. A. Tectônica e sedimentação da Bacia do Paraná. Atas do III Simpósio SulBrasileiro de Geologia, Curitiba, 1987. v. 1: 441477.

ZHOU, Q.; LEES, B.; TANG, G. (eds.). Advances in Digital Terrain Analysis. Series: Lecture Notes in Geoinformation and Cartography. Berlim: Springer-Verlag, 2008 